\title{
Quality Indicators and Survival Outcome in Stage IIIB-IVB Epithelial Ovarian Cancer Treated at a Single Institution
}

\author{
INGA STEINBERGA ${ }^{1}$, KJELL JANSSON ${ }^{2}$ and BENGT SORBE ${ }^{3}$ \\ ${ }^{1}$ Department of Obstetrics and Gynecology, Orebro University Hospital, Orebro, Sweden; \\ ${ }^{2}$ Department of Surgery, Orebro University Hospital, Orebro, Sweden; \\ ${ }^{3}$ Department of Oncology, Orebro University Hospital, Orebro, Sweden
}

\begin{abstract}
Background/Aim: To investigate the overall survival rate, quality indicators and treatment outcome in FIGO stage IIIB-IVB epithelial ovarian cancer at a University Hospital in Sweden between 2006 and 2015. Materials and Methods: A cohort of 110 patients was followed-up for 3-12 years after cancer diagnosis. Three main groups (primary surgery, neoadjuvant chemotherapy, palliative treatment), and six subgroups were defined according to treatment modality. Results: The mean age was 65 years. Patients were observed for a mean of 50 months. The total resection frequency was $83 \%$. Significant differences in overall survival at 5 years were observed between the groups varying from $60 \%$ to $12 \%$. Conclusion: Patient age, tumor stage and complete tumor removal at surgery were significant, independent prognostic factors of overall survival. Complication rate was a significant adverse prognostic factor in univariate analysis. Data discrepancy was observed between public quality reports and locally obtained data.
\end{abstract}

Ovarian cancer is the seventh most common cancer in women worldwide, according to the World Cancer Research Fund, and the sixth most common in Sweden (1). Even though ovarian cancer affects women in all ages, it is very unusual before the age of 30 , and common after the age of 55 where about two-thirds of affected women present the disease (2). Median age at diagnosis in Sweden is 65 years (3).

This article is freely accessible online.

Correspondence to: Inga Steinberga, Department of Obstetrics and Gynecology, Orebro University Hospital, 70185 Orebro, Sweden. Tel: +46 6021024, e-mail: inga.steinberga@bredband.net, inga.steinberga@regionorebrolan.se

Key Words: Epithelial ovarian cancer, survival, surgical treatment, quality factors.
Ovarian cancer has often no symptoms at early stages. Disease is diagnosed when it is generally advanced, usually at stage III or IV and spread outside the pelvis, to retroperitoneal lymph nodes or distant sites, such as liver, spleen or intrapleural fluid (3).

FIGO Ovarian Cancer Staging III-IV, 2013 is shown in Table I.

According to the Swedish Quality Register for Gynecological Cancer (SQRGC), the relative 5-year survival of epithelial ovarian cancer is $42 \%$ for stage III and $25 \%$ for stage IV patients in 2012-2016 (3).

The most common type of ovarian cancer is epithelial carcinoma $(85-90 \%)$ (4) and the remaining $10-15 \%$ are nonepithelial ovarian carcinomas, such as stromal and germ cell carcinomas. Five main types of epithelial carcinomas can be distinguished: high-grade serous (HGSOC; 70\%), endometrioid (ENOC; 10\%), clear cell (CCOC; 10\%), mucinous (MOC; $3 \%$ ), and low-grade serous (LGSOC; <5\%) (3). HGSOC is the most common type of epithelial ovarian cancer, considered to be chemotherapy sensitive and to have high prevalence of p53 mutations and generally poor outcome. The efficacy of platinum-based combined chemotherapy is higher in HGSOC than in LGSOC (5). LGSOC is typically present in younger women and has a good prognosis, despite being almost not sensitive to chemotherapy. Primary radical surgery favors prognosis in LGSOC (5). MOC and CCOC are associated with inferior outcome (6), but complete primary cytoreduction favors survival (7).

Currently, there are the following options of primary treatment of advanced ovarian cancer (i) Primary macroscopic radical surgery followed by adjuvant platinumbased combined chemotherapy is the most recommended treatment modality (7). Macroscopic radical surgery involves extensive removal of all visible tumor tissue to achieve no macroscopically visible residual disease $(0 \mathrm{~mm})$. Clinical guidelines recommend primary surgery for patients with advanced ovarian cancer if there is a high likelihood of achieving complete cytoreduction with acceptable morbidity $(8,9)$. It was confirmed already in 2009 by du Bois et al. 
IIIA (Positive retroperitoneal lymph nodes and/or microscopic metastasis beyond the pelvis)

IIIA1 Positive retroperitoneal lymph nodes only

IIIA1 Metastasis $\leq 10 \mathrm{~mm}$

IIIA1 Metastasis $>10 \mathrm{~mm}$

IIIA2 Microscopic, extrapelvic (above the brim) peritoneal involvement \pm positive retroperitoneal lymph nodes

IIIB Macroscopic, extrapelvic, peritoneal metastasis $\leq 2 \mathrm{~cm} \pm$ positive retroperitoneal lymph nodes. Includes extension to capsule of liver/spleen

IIIC Macroscopic, extrapelvic, peritoneal metastasis $>2 \mathrm{~cm} \pm$ positive retroperitoneal lymph nodes. Includes extension to capsule of liver/spleen

STAGE IV: Distant metastasis excluding peritoneal metastasis

IVA Pleural effusion with positive cytology

IVB Hepatic and/or splenic parenchymal metastasis, metastasis to extraabdominal organs (including inguinal lymph nodes and lymph nodes outside of the abdominal cavity)

that overall survival is significantly better when cancer is treated with primary cytoreduction with no visible residual cancer tissue $(0 \mathrm{~mm})(7)$. Intention within macroscopic radical surgery in FIGO III-IV disease has changed a lot over the past 10 years by striving for direct upfront retroperitoneal dissection and diaphragmatic stripping, splenectomy, gastrointestinal and partial liver resection and pelvic peritonectomy (9-12).

(ii) Primary tumor reducing surgery followed by adjuvant platinum-based combined chemotherapy involves an attempt to remove most of tumor masses with little remaining visible tumor tissue $(>0 \mathrm{~mm})$ when radical resection is considered impossible. The results of the wellknown Bristow meta-analysis have confirmed that every $10 \%$ increase in maximum tumor reduction is associated with a $5.5 \%$ increase in median survival in ovarian cancer stage III-IV (13).

(iii) Surgery after neoadjuvant chemotherapy or delayed primary surgery is usually administered as 2-4 cycles of neoadjuvant chemotherapy followed by cytoreductive surgery within 6 weeks. Based on two preceding studies, EORTC55971 and CHORUS, the latest phase III randomized trial from Japan as well as studies by Vergote et al. have demonstrated non-inferiority of neoadjuvant chemotherapy on overall survival $(14,15)$.

(iv) Primary palliative treatment is administered as a singleagent dose-reduced chemotherapy without curative intention or as symptomatic treatment. There is little data on survival at primary palliative treatment in ovarian cancer $(16,17)$.

(v) Hyperthermic intraperitoneal chemotherapy (HIPEC) administered at the time of primary or interval cytoreductive surgery. This method has been developed to combine surgical radicality with heated intraperitoneal chemotherapy to expose the remaining tumor to high concentrations of cytotoxic drugs to accomplish further microscopic cytoreduction. The overall evidence regarding the value of HIPEC in treatment of epithelial ovarian cancer has been the subject for debates since decades.
The value of performing a full lymphadenectomy in advanced ovarian cancer is a subject of debate. It has been proposed earlier that systematic pelvic and paraaortic lymphadenectomy could facilitate cytoreduction (9), favor 5year overall- and progression-free survival in randomized clinical trials, and reduce recurrence rate (18). However, a study by Harter et al. did not confirm the association of systematic pelvic and paraaortic lymphadenectomy with longer overall or progression-free survival, but has suggested that it contributes to a higher incidence of postoperative complications (19).

With intention to achieve and assure the highest quality of clinical care and subsequent survival, surgical treatment of ovarian cancer is increasingly being centralized and Standardized Care Process flow has been introduced in Sweden (1). The clinical data are documented in different National Quality Registries (20) and databases. The National Swedish Cancer Register (NCR), started 1958, is the most established with coverage rate $96 \%$ for epithelial ovarian cancer in 2017 (21). The NCR manages all cancer cases registered in Sweden via the web-based platform INCA (Information Network for Cancer care) that collaborates with the Swedish Quality Register for Gynecological Cancer (SQRGC). The SQRGC is considered to be of adequate quality in order to be used as a basis for research (21).

Based on current registers and our studies of interest we performed a survival review that is shown in Table II.

\section{Materials and Methods}

The study protocol was approved by the Regional Ethics Board (ref: Uppsala 2016/286). A cohort of 110 patients with FIGO stage IIIBIVB epithelial ovarian cancer was identified during 2006-2015 and followed-up 3-12 years after the primary diagnosis at the Department of Obstetrics and Gynecology, Orebro University Hospital, Sweden. The follow-up terminated January 01, 2018. Survival rate as well as median survival were calculated. Date of death was obtained from the Swedish Cause of Death Register database. Treatment was classified into the following groups according to the Figure 1 . 
Table II. Review of current register and studies on survival.

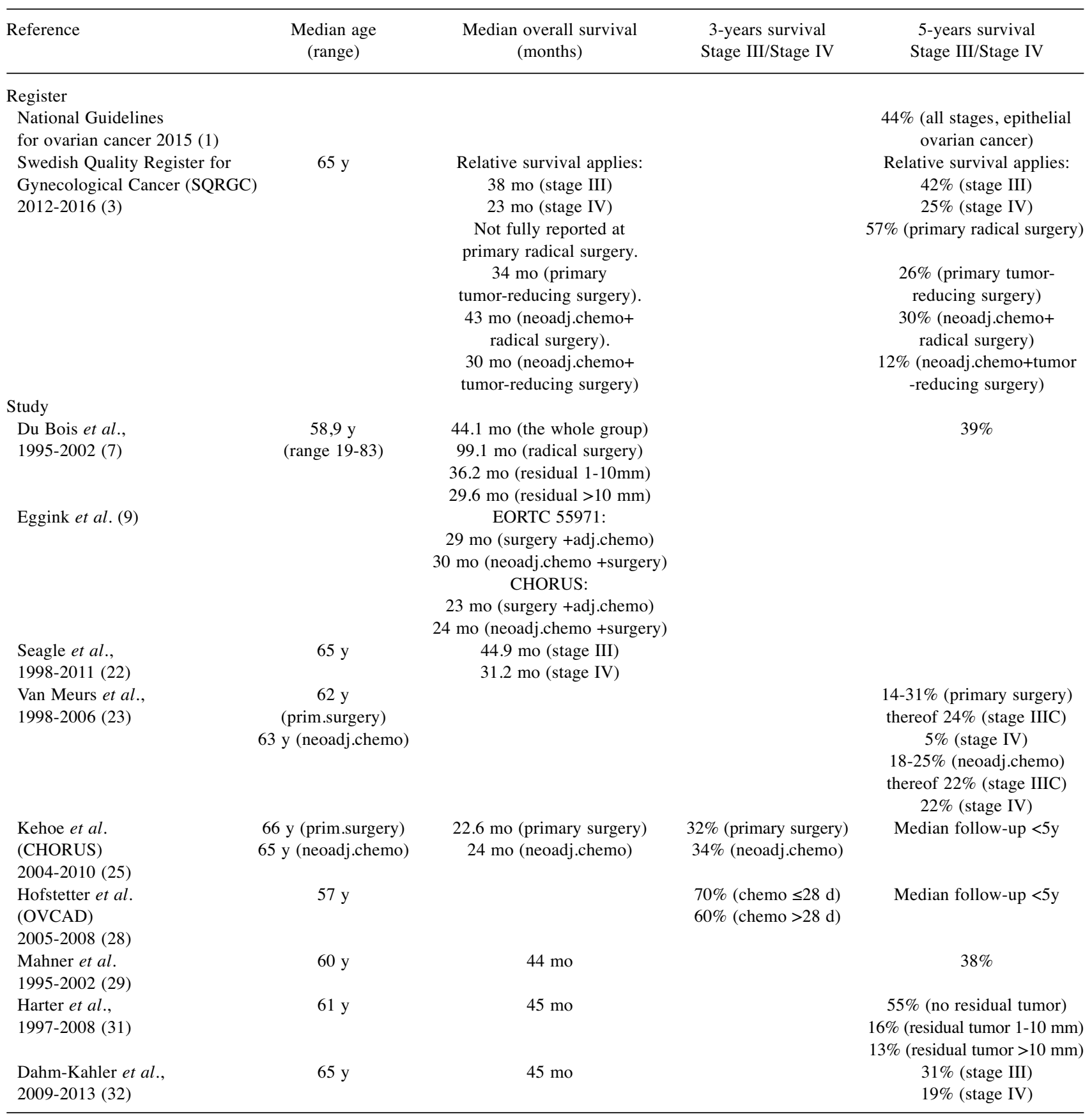

Primary cytoreductive surgery followed by adjuvant platinum-based combined chemotherapy. Radical surgery if no visible residual cancer tissue $(0 \mathrm{~mm})$ was left. Besides gynecological surgery, the following procedures were included: omentectomy, peritonectomy, lymphadenectomy, colectomy, resection of small intestine, splenectomy, resection of pancreas and liver. The surgical treatment was followed by adjuvant platinum-based chemotherapy (Group A).
There were no patients who did not receive adjuvant chemotherapy after macroscopically radical surgery (Group B).

Tumor-reducing surgery was defined if surgery was performed and visible tumors $(>0 \mathrm{~mm})$ remained, due to multiple metastases on the small intestines or tumor sites where radical resection was considered impossible. Treatment was followed by either adjuvant platinum-based chemotherapy (Group C) or no adjuvant chemotherapy (Group D). 


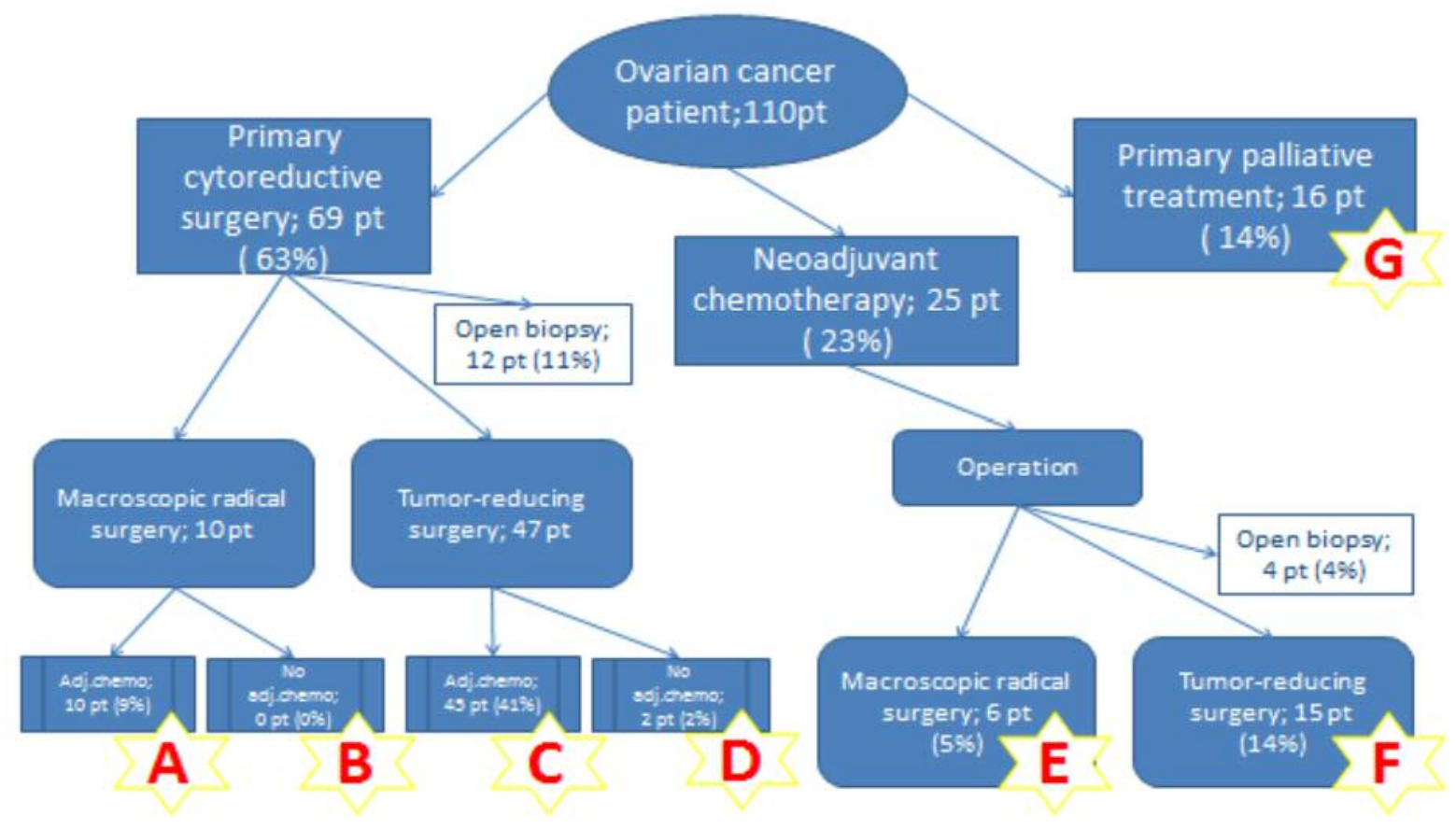

Figure 1. Flowchart of treatment groups.

Table III. Characteristics of the treatment groups.

\begin{tabular}{|c|c|c|c|c|c|c|}
\hline Group & $\begin{array}{l}\text { Stage, } \\
\text { III-IV }\end{array}$ & $\begin{array}{c}\text { Total, } \\
\mathrm{n}=110 \\
\mathrm{~N}(\% \text { of total })\end{array}$ & $\begin{array}{c}\text { Age, years } \\
\text { (mean, range) }\end{array}$ & $\begin{array}{c}\text { 3-years } \\
\text { survival }(\%)\end{array}$ & $\begin{array}{c}\text { 5-years } \\
\text { survival }(\%)\end{array}$ & $\begin{array}{c}\text { Median overall } \\
\text { survival (months) }\end{array}$ \\
\hline $\begin{array}{l}\text { A } \\
\text { B }\end{array}$ & III-10 & $\begin{array}{c}10(9 \%) \\
0\end{array}$ & 62 y (42-67) & $80 \%$ & $60 \%$ & $44+$ \\
\hline $\mathrm{C}$ & $\begin{array}{l}\text { III-40 } \\
\text { IV-5 }\end{array}$ & $45(41 \%)$ & 64 y $(37-83)$ & $46 \%$ & $30 \%$ & 35 \\
\hline D & $\begin{array}{l}\text { III-1 } \\
\text { IV-1 }\end{array}$ & $2(2 \%)$ & 73 y $(62-84)$ & & & \\
\hline $\mathrm{E}$ & $\begin{array}{l}\text { III-3 } \\
\text { IV-3 }\end{array}$ & $6(5 \%)$ & 67 y (48-77) & $67 \%$ & $33 \%$ & 45 \\
\hline $\mathrm{F}$ & $\begin{array}{l}\text { III-6 } \\
\text { IV-9 }\end{array}$ & $15(13 \%)$ & 67 y (40-71) & $50 \%$ & $21 \%$ & 34 \\
\hline G & $\begin{array}{c}\text { III-4 } \\
\text { IV-12 }\end{array}$ & $16(14 \%)$ & 74 y $(57-85)$ & $25 \%$ & $12 \%$ & 14 \\
\hline
\end{tabular}

Neoadjuvant platinum-based combined chemotherapy followed by delayed cytoreductive surgery was applied with intention to reduce tumor masses and strives for maximal cytoreduction at surgery.

Radical surgery if no visible residual cancer tissue $(0 \mathrm{~mm})$ was left (Group E).

Tumor-reducing surgery was defined if surgery was performed and visible tumors remained (Group F).

Primary palliative treatment was administered as chemotherapy without curative intention (Group G).
Laparotomy and only biopsy with or without divergent stoma were performed. This group was not included in the survival analysis.

Statistical analysis. Survival analyses using Kaplan-Meier technique were used to estimate overall survival (OS). Univariate and multivariate Cox proportional regression analyses (HR, 95\%CI, $p$ value) were performed to evaluate and compare prognostic factors contributing to overall survival. Pearson chi-square $\left(\chi^{2}\right.$-test) was used to compare survival difference between multiple groups as well 


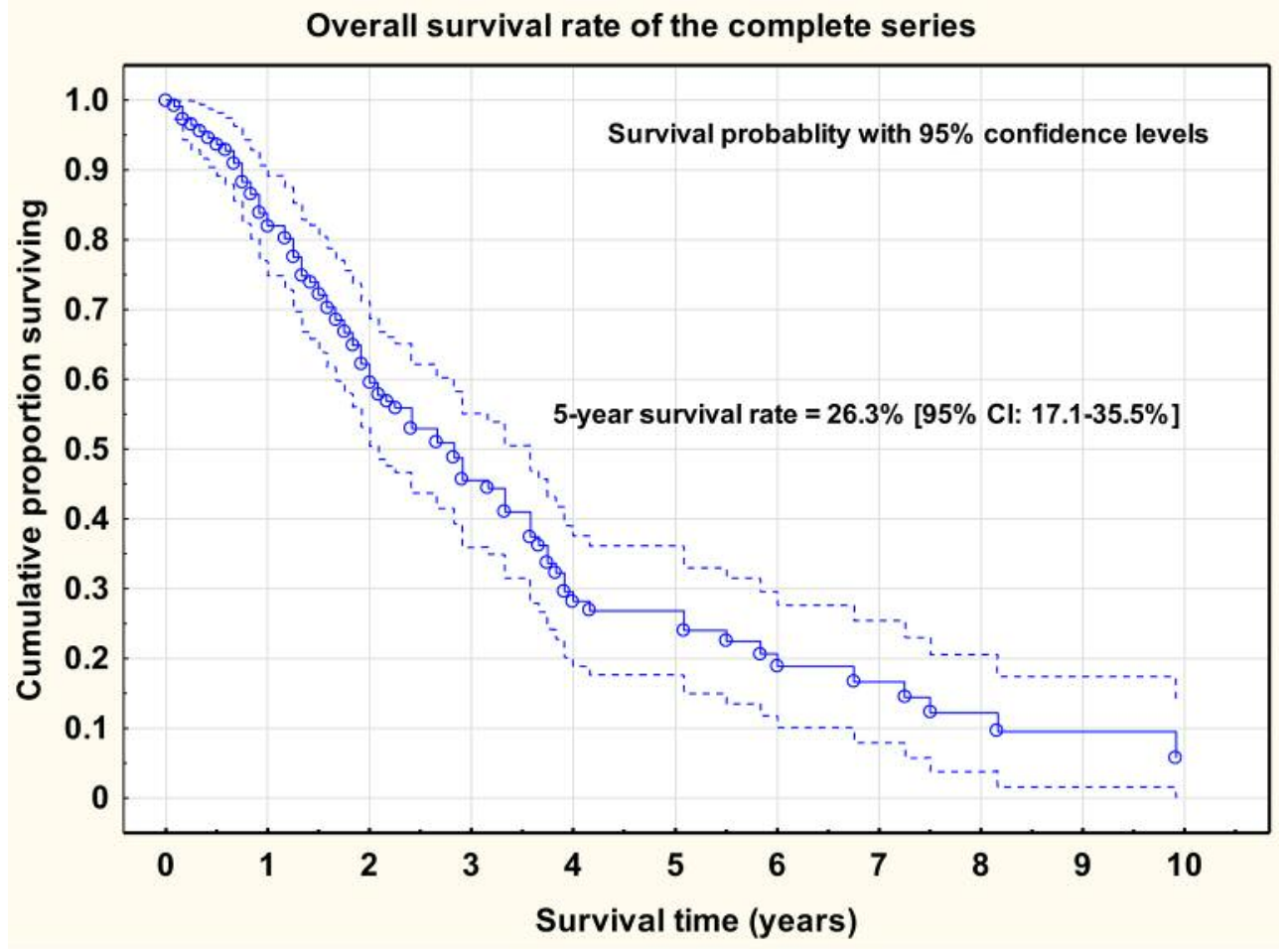

Figure 2. Overall survival rate of the complete series $(n=110)$, inclusive of the survival probability and the $95 \%$ confidence intervals.

as differences in proportions. The $t$-test was used to compare differences in continuous variables. A $p$-value $<0.05$ was considered as statistically significant. SPSS (version 25) and Statistica (version 13) were used for statistical analyses.

\section{Results}

The mean age of the complete series was 65 years (range=2785 years). Age was a significant prognostic factor for overall survival rate [Cox univariate proportional regression analysis; $\mathrm{HR}=1.028(95 \% \mathrm{CI}=1.005-1.053), p=0.019]$. The 5-year overall survival rate of the complete series was $26 \%(95 \% \mathrm{CI}=17.1$ $35.5 \%$ ) and the median survival was 34 months.

Overall survival rate of the complete series $(n=110)$, inclusive of the survival probability and the $95 \%$ confidence intervals is shown in Figure 2.

The mean observation time for patients alive was 50 months (range $=27-125$ months). The tumor stage distribution was $75(68 \%)$ FIGO stage III and 35 (32\%) FIGO stage IV.

Characteristics of the treatment groups is shown in Table III.

There was a highly significant (log-rank test; $p<0.01$ ) difference in survival between stage III $(34 \%)$ and stage IV (9\%) patients. In the primary surgery group complete cytoreduction was achieved in $18 \%$ and in the neoadjuvant group in $28 \%$ (chi-square test; $p=0.320$ ). The majority of the tumors $(87 \%)$ was high-grade serous carcinomas (HGSC).
In $12(11 \%)$ out of 69 patients who were initially planned for primary surgery (Group A-D), open biopsy of the oment, peritoneal surfaces or ovaries was performed and/or an intestinal stoma was applied. All these 12 patients received platinum-based combined chemotherapy followed by cytoreductive surgery in 4 cases. In the neoadjuvant chemotherapy group (Group E-F), open biopsy was performed in 4 patients due to poor response to the treatment and preoperative findings of multiple tumor growth on the surface of the small intestine.

There was a highly significant (chi-square test; $p<0.01$ ) difference between the five treatment groups with regard to overall survival rate, varying between $60 \%$ (Group A) and $12 \%$ (Group G) at 5 years.

Overall survival rate versus treatment group (A-G) is shown in Figure 3.

No significant difference was observed between primary macroscopically radical surgery (Group A) versus delayed macroscopically radical surgery (Group E) (log-rank test; $p=0.374)$.

Neither was there any significant difference between primary tumor-reducing surgery (Group C) versus delayed tumor-reducing surgery (Group F) (log-rank test; $p=0.865$ ).

No significant difference was noted between the groups treated with primary surgery (Group A and C) and the groups treated with neoadjuvant chemotherapy and delayed surgery 


\section{Overall survival rate vs. treatment group}

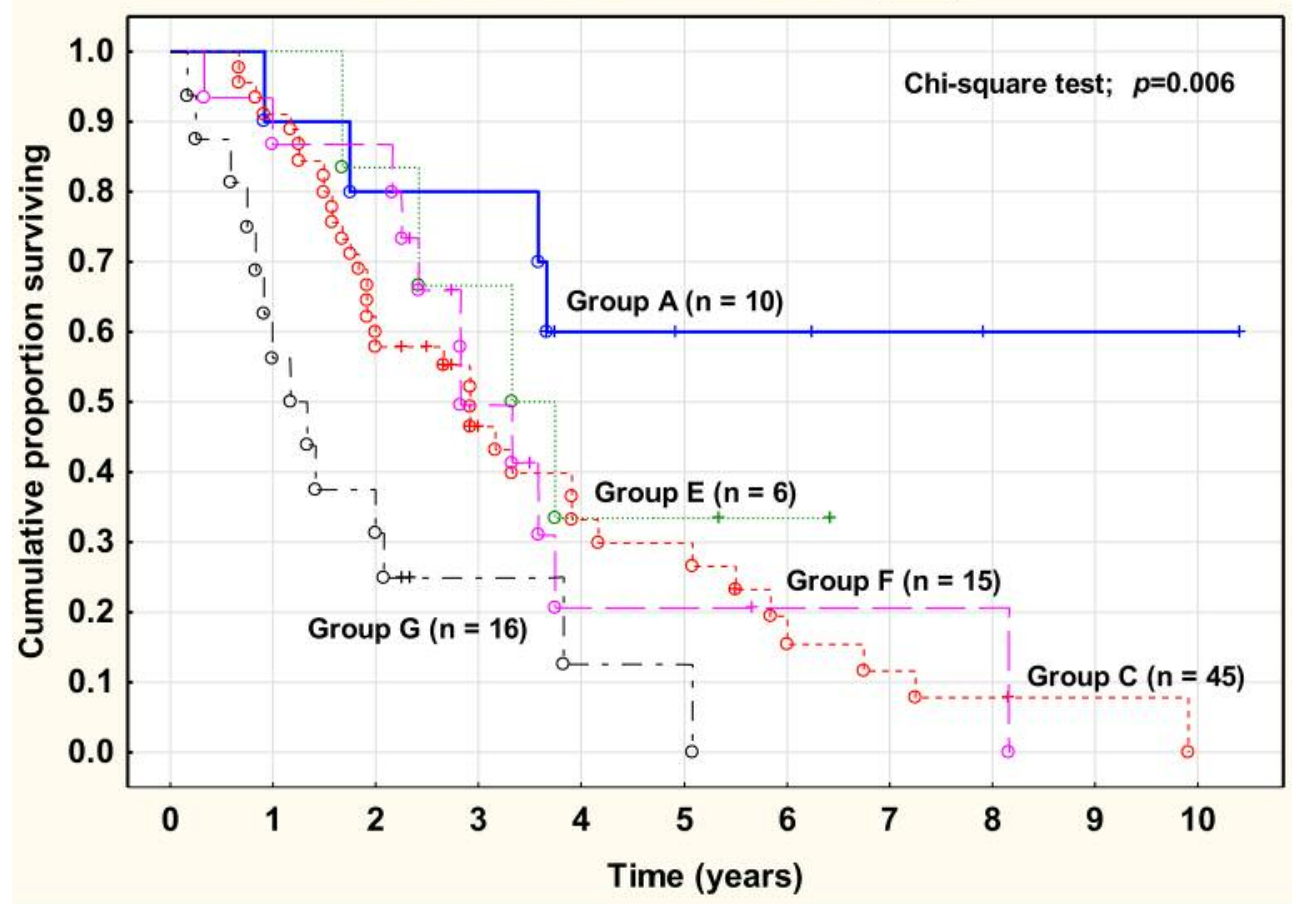

Figure 3. Overall survival rate versus treatment group (A-G).

(Group E and F) (log-rank test; p =0.929). After correction for the difference in stage distribution there was still no significant difference between the primary surgery groups and the neoadjuvant groups.

Overall survival rate according to treatment modality is shown in Figure 4.

Univariate and multivariate Cox proportional regression analyses were used to evaluate prognostic factors for overall survival rate.

Prognostic factors for overall survival rate. Cox proportional regression analyses are shown in Table IV.

The median time between primary surgery and start of chemotherapy was 38 days (range $=14-126$ days). This time was not a significant prognostic factor for overall survival rate [Cox univariate proportional regression analysis; $\mathrm{HR}=1.009 \quad(95 \% \mathrm{CI}=0.995-1.023), p=0.194]$. Even the analysis of two groups, less than the median value and larger than the median value, did not show any significant difference (log-rank test; $p=0.148)$. A cut-off level of 22 days was not possible to use for calculations in these series.

Surgical complications (minor and major) were recorded in 14 out of all 94 surgery cases $(15 \%)$ and were categorized as major complications in $8 \%$ (stoma necrosis/infection and reoperation, bowel obstruction and reoperation, anastomotic leakage and reoperation, wound rupture/abscess and reoperation followed by multi organ failure), and minor complications in $4 \%$ (wound infection, urinary infection, pneumonia). Cox univariate proportional regression analysis showed that surgical complications were a significant $[\mathrm{HR}=1.932$, (95\% CI $=1.042$ $3.584), p=0.033$ ] adverse prognostic factor for overall survival probability.

The overall 30-days mortality was $2 \%$ and thereof $1 \%$ due to surgical complications in terms of wound rupture, abscess followed by reoperation and multi organ failure (Group F, FIGO stage IV). The second 30-days mortality occurred in a patient at FIGO stage IV who received neoadjuvant chemotherapy followed by open biopsy only. However, this patient developed renal failure afterwards.

The number of days at hospital was a significant prognostic factor with regard to overall survival rate [Cox univariate proportional regression analysis; $\mathrm{HR}=1.046(95 \% \mathrm{CI}=1.014$ $1.080) ; p=0.005]$. However, the surgery time and the amount of bleeding were non-significant prognostic factors.

\section{Discussion}

This study presents data from an individual gynecological center in Sweden without any regard to quality registers.

Mean age at diagnosis corresponds to the general average for ovarian cancer patients in Sweden. Despite the high mean 


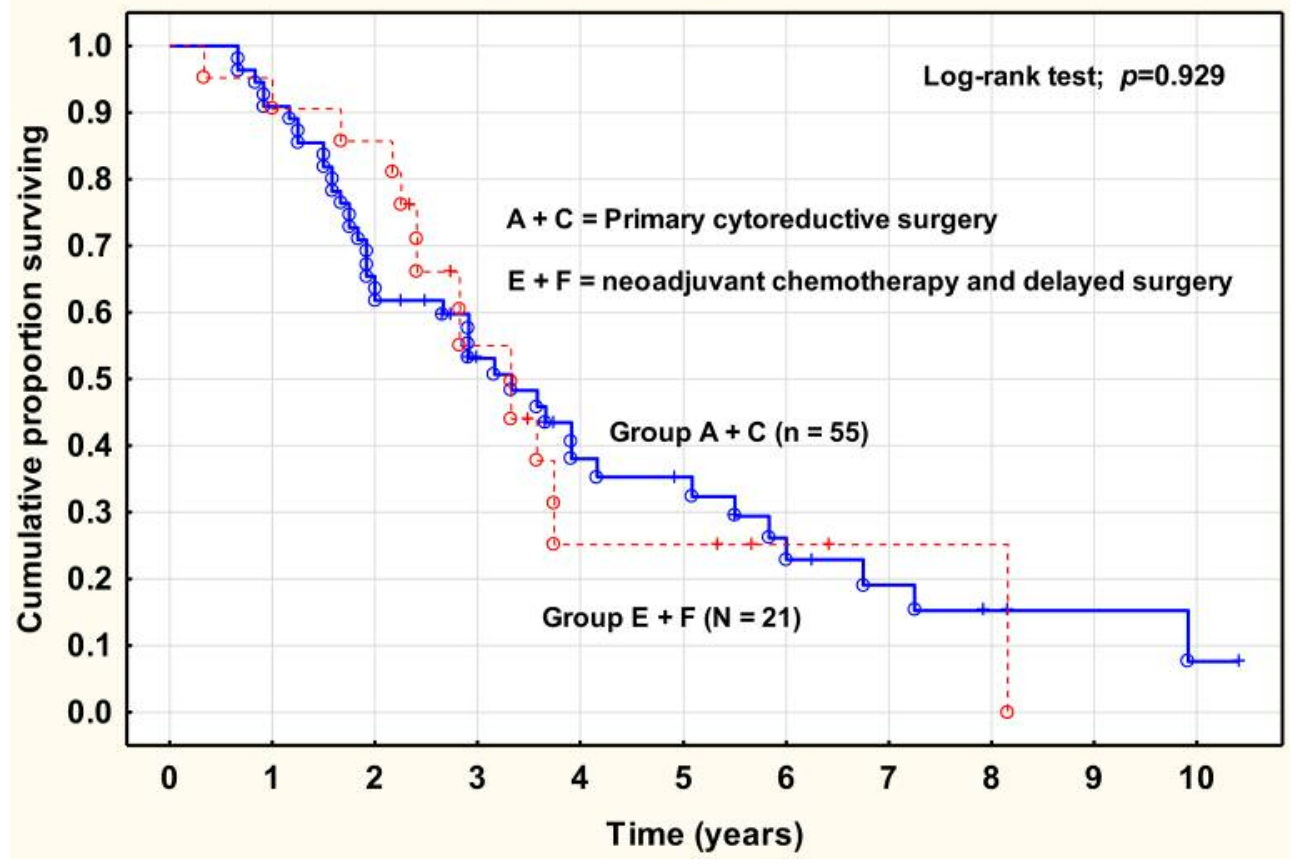

Figure 4. Overall survival rate according to treatment modality.

age of the patients and one third of the tumors being in FIGO stage IV the total resection frequency was $83 \%$. Surgery was performed in close collaboration with colorectal surgeons and urologists depending on intraoperative findings and surgical intention. Surgical efforts to achieve no remaining macroscopic tumor were of significant prognostic importance for overall survival. All patients in Group A were in FIGO stage III. The surgical intervention in this group was characterized by $30 \%$ colon and rectum resection, lymph node resection and small bowel resection, and in $10 \%$ also liver resection. In all cases, hysterectomy, removal of adnexa, total omentectomy and multiple peritoneal excisions were performed. The overall survival rate was highest in Group A, corresponding to $60 \%$. Furthermore, $80 \%$ of the patients in Group A were able to undergo primary surgery within less than 24 days from diagnosis (mean 10 days). There was no significant survival benefit observed when primary radical surgery was compared with delayed radical surgery after neoadjuvant chemotherapy. It is important to note that both Group A $(n=10)$ and Group E $(n=6)$ were small and that true significant statistical differences were difficult to show. Therefore, the importance of primary radical surgery versus delayed radical surgery cannot be settled in this study due to limited number of patients. Survival in Group A is in agreement with data from large database studies by Seagle et al. revealing a median survival of 44.9 months in FIGO stage III patients who underwent primary complete surgery (22).

Our data suggest up to $50 \%$ 3-year survival rate after tumor-reducing surgery in Groups $\mathrm{C}$ and F. Radical surgery was not possible in these groups, mostly due to multiple tumor growth on the surface of the small intestine. No significant difference in survival was observed between primary surgery groups and neoadjuvant groups after correction for difference in stage distribution. A tendency towards improved short-term survival (pattern of survival curves) was observed in the neoadjuvant group in stage IV, but the difference was not statistically significant. An analysis of the European Organization for Research and Treatment of Cancer (EORTC) randomized trial by van Meurs et al. has reported quite similar five-year survival rates in patients with large metastatic tumors in stage IIIC and less extensive metastatic tumors in stage IV at both primary surgery and neoadjuvant chemotherapy followed by cytoreductive surgery (23). It points out that neoadjuvant chemotherapy may prevent unnecessary postoperative morbidity and mortality $(24,25)$ and promote higher chances of achieving complete cytoreduction during surgery (9). However, the available randomized data on the role of neoadjuvant chemotherapy in survival are limited in patients with intraabdominal FIGO stage IIIC versus stage IIIC based on nodal status only (26). 
Table IV. Prognostic factors for overall survival rate. Cox proportional regression analyses.

\begin{tabular}{lccc}
\hline Univariate analyses & & & \\
\hline Factor & Hazard ratio & $95 \% \mathrm{CI}$ & $p$-Value \\
\hline Age (per year) & 1.028 & $1.005-1.053$ & 0.019 \\
FIGO stage (IV $v s$. III) & 2.012 & $1.264-3.201$ & 0.003 \\
Complete resection (no $v s$. yes) & 2.286 & $1.320-4.624$ & 0.021 \\
Primary surgery (no $v s$. yes) & 1.028 & $0.564-1.874$ & 0.929 \\
Time to chemotherapy (per day) & 1.009 & $0.995-1.023$ & 0.194 \\
Hospital stay (per day) & 1.046 & $1.014-1.080$ & 0.005 \\
Complications (yes $v s$. no) & 1.932 & $1.042-3.584$ & 0.037 \\
\end{tabular}

Multivariate analysis

\begin{tabular}{lccc}
\hline Factor & Hazard ratio & $95 \% \mathrm{CI}$ & $p$-Value \\
\hline Age (per year)* & 1.028 & $1.001-1.056$ & 0.039 \\
FIGO-stage (IV vs. III)* $^{*}$ Complete resection (no $v s$. yes)* $^{*}$ & 2.917 & $1.124-3.271$ & 0.017 \\
Hospital stay (per day) $_{\text {Complications (yes } v s . \text { no) }}$ & 1.022 & $1.107-4.643$ & 0.025 \\
& 1.758 & $0.887-1.060$ & 0.223 \\
\hline
\end{tabular}

*Significant and independent prognostic factors.

There are no studies yet on the impact of lead times on survival at our department. A study by Kommoss et al. has shown that implementation of an institutional quality assurance and disease management program for ovarian cancer care was associated with a significant improvement in the degree of surgeon and institutional compliance (27). Studies by Hofstetter et al. as well as Mahner et al. have confirmed $(28,29)$ that delayed initiation of adjuvant chemotherapy might compromise overall survival in patients with advanced serous (FIGO III-IV) ovarian cancer. However, these studies showed partly conflicting results and should be further discussed. In our study, no significant difference in overall survival rate was found between primary surgery and neoadjuvant chemotherapy groups with time delay shorter and longer than the median value (38 days). Centralization of advanced ovarian cancer surgery, performed by gynecological tumor surgeons, has been verified that improves the quality of treatment and survival (30-32). However, the patient volume of the hospital only does not provide conclusive evidence with respect to outcome measures (30). A Swedish population-based cohort study by Dahm-Kähler et al. has confirmed that centralization of advanced ovarian cancer surgery increased the relative 3-year survival rate (33).

Hyperthermic intraperitoneal chemotherapy (HIPEC) was never applied in patients with ovarian cancer in our center. The overall evidence addressing the value of HIPEC in epithelial ovarian cancer has been controversial during the last decades.
Some studies have suggested that age, peritoneal cancer index, CA-125, good performance status at cytoreduction as well as FIGO stage III might be associated with long-term survival (34-36). However, a Cochrane report revealed that despite that intraperitoneal treatment prolonged the progression-free survival it was associated with higher incidence of toxicity and more serious side effects, such as fever, fatigue, gastrointestinal complications, infections, metabolic effects and pain compared with intravenous treatment alone (37).

There are few published data from individual centers in Sweden regarding overall survival at advanced ovarian cancer. Most studies base their data on different registers that provide access to large data amount. According to the Swedish Quality Register for Gynecological Cancer, the relative 5-years survival in epithelial ovarian cancer all stages was $50 \%$ in Uppsala-Orebro region during 2011-2015 (3). However, the Swedish National Board of Health and Welfare reported a survival rate of $37 \%$ in Orebro (Open comparisons, 20102014). A separate retrospective study of all consecutive patients with ovarian cancer in all stages (not published) from the Department of Gynecological Oncology, Orebro University Hospital, treated during the period 1993-2009 encompassing 1481 patients revealed an overall survival rate of $51 \%$ and a cancer-specific survival rate of $54 \%$. Thus, there seems to be a discrepancy when data from our study as well as earlier data from Orebro compared to registry data presented during the last years. Clinical observations of our study revealed a favorable 5-year survival rate. Our study cannot further answer the register issue. However, we will emphasize the need of further quality studies to review data processing and validation in large registers and compare them with manual data analysis from individual centers. We believe that our survival data are in agreement with those of other regions and of the country as a whole.

Our data suggest that treatment of advanced ovarian cancer safely can be performed at centers with adequate number of patients and experienced tumor surgeons familiar with ovarian cancer surgery. Centralization of this surgery to a HIPEC-center is recommended only if future studies can provide conclusive evidence in favor of the use of HIPEC in ovarian cancer.

There are certain limitations of our study. This was an observational cohort study and patients were not randomized with regard to either treatment (primary surgery versus neoadjuvant therapy) or surgical extent (macroscopic radical versus only tumor-reducing surgery). Patients were not classified according to the peritoneal cancer index. The cohort and subgroups were small with a relatively short period of follow-up.

\section{Conflicts of Interest}

The Authors have no conflicts of interest regarding this study. 


\section{Authors' Contributions}

Inga Steinberga: Conception of the work, collection of data, statistical analysis and interpretation of data, drafting the work and writing manuscript. Accountancy for agreement for accuracy and integrity in all aspects of the work. Final approval of the version to be published. Kjell Jansson: Advice regarding design of the work. Contribution to evaluation and interpretation of clinical data, statistical analysis. Advice regarding surgical treatment and especially colorectal surgery at advanced ovarian carcinoma. Advice regarding composition of manuscript. Bengt Sorbe: Advice regarding gynecologic oncology and especially treatment of ovarian carcinoma. Contribution to evaluation of clinical data and statistical analyses. Advice regarding tables, figures and Discussion. General check of language matters.

\section{References}

1 Nationellt vårdprogram äggstockscancer 2015: Gällande vårdprogram äggstockscancer. Swedish. Available at https:// www.cancercentrum.se/samverkan/cancerdiagnoser/gynekologi/a ggstock/vardprogram/gallande-vardprogram-aggstockscancer/. Last accessed on 24th May 2019.

2 Cancer Treatment Centers of America: Ovarian cancer. English. Available at https://www.cancercenter.com/cancer-types/ovariancancer/risk-factors. Last accessed on 24th May 2019

3 Gynekologisk cancer: Nationell kvalitetsrapport från Svenska Kvalitetsregistret för Gynekologisk Cancer (SQRGS). Diagnosår:2012-Juni2016. Swedish. Available at http://www. kvalitetsregister.se/hittaregister/registerarkiv/gynekologiskcancer. 2325.html. Last accessed on 24th May 2019.

4 World Cancer Research Fund /American Institute for Cancer Research 2014: Diet, nutrition, physical activity and ovarian cancer. Available at https://www.aicr.org/continuous-updateproject/reports/ovarian-cancer-2014-report.pdf. Last accessed on 24th May 2019.

5 Grabowski JP, Harter P, Heitz F, Pujade-Lauraine E, Reuss A, Kristensen G, Ray-Coquard I, Heitz J, Traut A, Pfisterer J and $\mathrm{du}$ Bois A: Operability and chemotherapy responsiveness in advanced low-grade serous ovarian cancer. An analysis of the AGO Study Group metadatabase. Gynecol Oncol 140(3): 457462, 2016. PMID: 26807488. DOI: 10.1016/j.ygyno.2016.01.022

6 Mackay HJ, Brady MF, Oza AM, Reuss A, Pujade-Lauraine E, Swart AM, Siddiqui N, Colombo N, Bookman MA, Pfisterer J and du Bois A: Prognostic relevance of uncommon ovarian histology in women with stage III/IV epithelial ovarian cancer. Int J Gynecol Cancer 20(6): 945-952, 2010. PMID: 20683400. DOI: 10.1111/IGC.0b013e3181dd0110

7 du Bois A, Reuss A, Pujade-Lauraine E, Harter P, Ray-Coquard I and Pfisterer J: Role of surgical outcome as prognostic factor in advanced epithelial ovarian cancer: a combined exploratory analysis of 3 prospectively randomized phase 3 multicenter trials: by the Arbeitsgemeinschaft Gynaekologische Onkologie Studiengruppe Ovarialkarzinom (AGO-OVAR) and the Groupe d'Investigateurs Nationaux Pour les Etudes des Cancers de l'Ovaire (GINECO). Cancer 115(6): 1234-1244, 2009. PMID: 19189349. DOI: $10.1002 /$ cncr.24149

8 Wright AA, Bohlke K, Armstrong DK, Bookman MA, Cliby WA, Coleman RL, Dizon DS, Kash JJ, Meyer LA, Moore KN
Olawaiye AB, Oldham J, Salani R, Sparacio D, Tew WP, Vergote I and Edelson MI: Neoadjuvant chemotherapy for newly diagnosed, advanced ovarian cancer: Society of Gynecologic Oncology and American Society of Clinical Oncology Clinical Practice Guideline. Gynecol Oncol 143(1): 3-15, 2016. PMID: 27650684. DOI: 10.1016/j.ygyno.2016.05.022

9 Eggink FA, Koopmans CM and Nijman HW: Surgery for patients with newly diagnosed advanced ovarian cancer: which patient, when and extent? Curr Opin Oncol 29(5): 351-358, 2017. PMID: 28614136 . DOI: $10.1097 /$ CCO .0000000000000387

10 Makar AP, Tropé CG, Tummers P, Denys H and Vandecasteele $\mathrm{K}$ : Advanced Ovarian Cancer: Primary or Interval Debulking? Five categories of patients in view of the results of randomized trials and tumor biology: primary debulking surgery and interval debulking surgery for advanced ovarian cancer. Oncologist 21(6): 745-754, 2016. PMID: 27009938. DOI:10.1634/ theoncologist.2015-0239

11 Barnes W, Johnson J, Waggoner S, Barter J, Potkul R and Delgado G: Reverse hysterocolposigmoidectomy (RHCS) for resection of panpelvic tumors. Gynecol Oncol 42(2): 151-155, 1991. PMID: 1894175.

12 Chi DS, Eisenhauer EL, Zivanovic O, Sonoda Y, Abu-Rustum NR, Levine DA, Guile MW, Bristow RE, Aghajanian C and Barakat RR. Improved progression-free and overall survival in advanced ovarian cancer as a result of a change in surgical paradigm. Gynecol Oncol 114(1): 26-31, 2009. PMID: 19395008. DOI: 10.1016/j.ygyno.2009.03.018

13 Bristow RE, Tomacruz RS, Armstrong DK, Trimble EL and Montz FJ: Survival effect of maximal cytoreductive surgery for advanced ovarian carcinoma during the platinum era: a metaanalysis. J Clin Oncol 20(5): 1248-1259, 2002. PMID: 11870167. DOI: $10.1200 / \mathrm{JCO} .2002 .20 .5 .1248$

14 Vergote I, Amant F, Kristensen G, Ehlen T, Reed NS and Casado A: Primary surgery or neoadjuvant chemotherapy followed by interval debulking surgery in advanced ovarian cancer. Eur $\mathbf{J}$ Cancer 47: S88-92, 2011. PMID: 21944035. DOI: 10.1016/ S0959-8049(11)70152-6

15 Onda T, Satoh T, Saito T, Kasamatsu T, Nakanishi T, Nakamura K, Wakabayashi M, Takehara K, Saito M, Ushijima K, Kobayashi H1, Kawana K, Yokota H, Takano M, Takeshima N, Watanabe Y, Yaegashi N, Konishi I, Kamura T and Yoshikawa $\mathrm{H}$ : Comparison of treatment invasiveness between upfront debulking surgery versus interval debulking surgery following neoadjuvant chemotherapy for stage III/IV ovarian, tubal, and peritoneal cancers in a phase III randomised trial: Japan Clinical Oncology Group Study JCOG0602. Eur J Cancer 64: 22-31, 2016. PMID: 27323348. DOI: 10.1016/j.ejca.2016.05.017

16 Chan R and Webster J: End-of-life care pathways for improving outcomes in caring for the dying. Cochrane Database Syst Rev 2010(1): CD008006. PMID: 26866512. DOI: 10.1002/146518 58.CD008006.pub4

17 Temel JS, Greer JA, Muzikansky A, Gallagher ER, Admane S, Jackson VA, Dahlin CM, Blinderman CD, Jacobsen J, Pirl WF, Billings JA and Lynch TJ: Early palliative care for patients with metastatic non-small-cell lung cancer. N Engl J Med 363(8): 733742, 2010. PMID: 20818875. DOI: 10.1056/NEJM oa1000678

18 Zhou J, Shan G and Chen Y: The effect of lymphadenectomy on survival and recurrence in patients with ovarian cancer: a systematic review and meta-analysis. Jpn J Clin Oncol 46(8): 718-726, 2016. PMID: 27272175. DOI: 10.1093/jjco/hyw068 
19 Harter P, Sehouli J, Lorusso D, Reuss A, Vergote I, Marth C, Kim JW, Raspagliesi F, Lampe B, Aletti G, Meier W, Cibula D, Mustea A, Mahner S, Runnebaum IB, Schmalfeldt B, Burges A, Kimmig R, Scambia G, Greggi S, Hilpert F, Hasenburg A, Hillemanns P, Giorda G, von Leffern I, Schade-Brittinger C, Wagner U and du Bois A: A randomized trial of lymphadenectomy in patients with advanced ovarian neoplasms. N Engl J Med 380(9): 822-832, 2019. PMID: 30811909. DOI: 10.1056/NEJMoa1808424

20 Nationella Kvalitetsregister, 2016: Kunskap för bättre vård och omsorg. Swedish. Available at http://kvalitetsregister.se/ hittaregister/kategorier/cancer.1964.html. Last accessed on 24th May 2019.

21 Rosenberg P, Kjølhede P, Staf C, Bjurberg M, Borgfeldt C, Dahm-Kähler P, Hellman K, Hjerpe E, Holmberg E, Stålberg K, Tholander B, Åvall Lundqvist E and Högberg T: Data quality in the Swedish Quality Register of Gynecologic Cancer - a Swedish Gynecologic Cancer Group (SweGCG) study. Acta Oncol 57(3): 346-353, 2018. PMID: 28828920. DOI: 10.1080/ 0284186X.2017.1366048

22 Seagle BL, Graves S, Strohl AE and Shahabi S: Survival after primary debulking surgery compared with neoadjuvant chemotherapy in advanced ovarian cancer: A National Cancer Database Study. Int J Gynecol Cancer 27(8): 1610-1618, 2017. PMID: 28763362 DOI: 10.1097/IGC.0000000000001072

23 van Meurs HS, Tajik P, Hof MH, Vergote I, Kenter GG, Mol BW, Buist MR and Bossuyt PM: Which patients benefit most from primary surgery or neoadjuvant chemotherapy in stage IIIC or IV ovarian cancer? An exploratory analysis of the European Organisation for Research and Treatment of Cancer 55971 randomised trial. Eur J Cancer 49(15): 3191-3201, 2013. PMID: 23850170. DOI: 10.1016/j.ejca.2013.06.013

24 Vergote I, Amant F, Kristensen G, Ehlen T, Reed NS and Casado A: Primary surgery or neoadjuvant chemotherapy followed by interval debulking surgery in advanced ovarian cancer. Eur J Cancer 47(3): S88-92, 2011. PMID: 21944035. DOI: 10.1016/ S0959-8049(11)70152-6

25 Kehoe S, Hook J, Nankivell M, Jayson GC, Kitchener H, Lopes T, Luesley D, Perren T, Bannoo S, Mascarenhas M, Dobbs S, Essapen S, Twigg J, Herod J, McCluggage G, Parmar M and Swart AM: Primary chemotherapy versus primary surgery for newly diagnosed advanced ovarian cancer (CHORUS): an openlabel, randomised, controlled, non-inferiority trial. Lancet 386(9990): 249-257, 2015. PMID: 26002111. DOI: 10.1016/ S0140-6736(14)62223-6

26 Vergote I, du Bois A, Amant F, Heitz F, Leunen K and Harter P: Neoadjuvant chemotherapy in advanced ovarian cancer: On what do we agree and disagree? Gynecol Oncol 128(1): 6-11, 2013. PMID: 23006973. DOI: 10.1016/j.ygyno.2012.09.013

27 Kommoss S, Harter P, Traut A, Strutas D, Riegler N, Buhrmann $\mathrm{C}$, Gomez $\mathrm{R}$ and du Bois A: Compliance to consensus recommendations, surgeon's experience, and introduction of a quality assurance and manangement program. Influence on therapy of early-stage ovarian carcinoma. Int J Gynecol Cancer 19(4): 787-793, 2009. PMID: 19509589. DOI: 10.1111/IGC.0b0 $13 \mathrm{e} 3181 \mathrm{a} 3 \mathrm{a} 551$

28 Hofstetter G, Concin N, Braicu I, Chekerov R, Sehouli J, Cadron I, Van Gorp T, Trillsch F, Mahner S, Ulmer H, Grimm C, Castillo-Tong DC, Zeillinger R, Zeimet AG and Vergote I: The time interval from surgery to start of chemotherapy significantly impacts prognosis in patients with advanced serous ovarian carcinoma - analysis of patient data in the prospective OVCAD study. Gynecol Oncol 131(1): 15-20, 2013. PMID: 23877013. DOI: $10.1016 /$ j.ygyno.2013.07.086

29 Mahner S, Eulenburg C, Staehle A, Wegscheider K, Reuss A, Pujade-Lauraine E, Harter P, Ray-Coquard I, Pfisterer J and du Bois A: Prognostic impact of the time interval between surgery and chemotherapy in advanced ovarian cancer: analysis of prospective randomised phase III trials. Eur J Cancer 49(1): 142149, 2013. PMID: 22921185. DOI: 10.1016/j.ejca.2012.07.023

$30 \mathrm{du}$ Bois A, Rochon J, Pfisterer J and Hoskins WJ: Variations in institutional infrastructure, physician specialization and experience, and outcome in ovarian cancer: a systematic review. Gynecol Oncol 112(2): 422-436, 2009. PMID: 18990435. DOI: 10.1016/j.ygyno.2008.09.036

31 Harter P, Muallem ZM, Buhrmann C, Lorenz D, Kaub C, Hils R, Kommoss S, Heitz F, Traut A and du Bois A: Impact of a structured quality management program on surgical outcome in primary advanced ovarian cancer. Gynecol Oncol 121(3): 615619, 2011. PMID: 21414656. DOI: 10.1016/j.ygyno.2011.02.014

32 Dahm-Kähler P, Borgfeldt C, Holmberg E, Staf C, Falconer H, Bjurberg M, Kjölhede P, Rosenberg P, Stålberg K, Högberg T and Åvall-Lundqvist E: Population-based study of survival for women with serous cancer of the ovary, fallopian tube, peritoneum or undesignated origin - on behalf of the Swedish gynecological cancer group (SweGCG). Gynecol Oncol 144(1): 167-173, 2017. PMID: 27817932. DOI: 10.1016/j.ygyno. 2016.10.039

33 Dahm-Kahler P, Palmqvist C, Staf C, Holmberg E and Johannesson L: Centralized primary care of advanced ovarian cancer improves complete cytoreduction and survival - A population-based cohort study. Gynecol Oncol 142(2): 211-216, 2016. PMID: 27238084. DOI: 10.1016/j.ygyno.2016.05.025

34 Le Saux O, Decullier E, Freyer G, Glehen O and Bakrin N: Long-term survival in patients with epithelial ovarian cancer following cytoreductive surgery and hyperthermic intraperitoneal chemotherapy (HIPEC). Int J Hyperthermia 35(1): 652-657, 2018. PMID: 30295114. DOI: 10.1080/02656736.2018.1518544

35 van Leeuwen BL, Graf W, Pahlman L and Mahteme H: Swedish experience with peritonectomy and HIPEC. HIPEC in peritoneal carcinomatosis. Ann Surg Oncol 15(3): 745-753, 2008. PMID: 18057988. DOI: $10.1245 / \mathrm{s} 10434-007-9700-5$

36 van Driel WJ, Koole SN, Sikorska K, Schagen van Leeuwen JH, Schreuder HWR, Hermans RHM, de Hingh IHJT, van der Velden J, Arts HJ, Massuger LFAG, Aalbers AGJ, Verwaal VJ, Kieffer JM, Van de Vijver KK, van Tinteren H, Aaronson NK and Sonke GS: Hyperthermic Intraperitoneal Chemotherapy in Ovarian Cancer. N Engl J Med 378(3): 230-240, 2018. PMID: 29342393. DOI: 10.1056/NEJMoa 1708618

37 Jaaback K, Johnson $\mathrm{N}$ and Lawrie TA: Intraperitoneal chemotherapy for the initial management of primary epithelial ovarian cancer. Cochrane Database Syst Rev (11): CD005340, 2011. PMID: 22071822. DOI: 10.1002/14651858.CD005 40.pub3

Received May 31, 2019

Revised June 28, 2019

Accepted July 3, 2019 